\title{
ESTUDO DA ADESÃO DE BIOFILME BACTERIANO EM SISTEMAS DE FERMENTAÇÃO DE GÁS DE SÍNTESE
}

\author{
F. M. B. COELHO ${ }^{1}$, R. R. RIBEIRO ${ }^{2}$, P. F. F. AMARAL ${ }^{2}$ e T. F. FERREIRA ${ }^{3}$ \\ ${ }^{1}$ Universidade Federal do Rio de Janeiro, Faculdade de Engenharia Química \\ ${ }^{2}$ Universidade Federal do Rio de Janeiro, Departamento de Engenharia Bioquímica \\ 3 Universidade Federal do Rio de Janeiro, Departamento de Processos Orgânicos \\ E-mail para contato: fabicoelhoquimica@gmail.com
}

\begin{abstract}
RESUMO - A análise da aderência de biofilme celular e constituintes do meio foi feita através da massa das membranas HA em Éster de Celulose e Fluorpore (FH), presentes em frascos de penicilina utilizados na fermentação de gás de síntese para produção de etanol. O experimento mostrou que a adesão celular à superfície não só é composta por interações físicas, mas também químicas devido ao caráter hidrofóbico ou hidrofílico das membranas. A membrana $\mathrm{FH}$, hidrofóbica, apresentou um aumento mássico expressivo em células de $10 \%$ em relação à membrana HA, hidrofílica, que apresentou aumento mássico negativo. Foi possível observar também que os componentes do meio aderiram mais à superfície da membrana hidrofílica (em aproximadamente 10\%) do que da membrana hidrofóbica (em 5\%). Isso possivelmente indica uma competição na superfície dessas membranas entre células e constituintes do meio, impedindo o crescimento do biofilme na membrana HA não só por conta das interações físicas e químicas, mas também por impedimento estérico.
\end{abstract}

\section{INTRODUÇÃO}

A busca por energias limpas e renováveis tem aumentado ao longo dos últimos anos devido à necessidade de diminuição no uso de fontes oriundas de combustíveis fósseis, cuja queima gera resíduos que impactam negativamente o meio ambiente com geração de gases estufa. Dessa forma, muitos estudos para a produção de biocombustíveis ganharam força no Brasil, aumentando o interesse pela produção de biodiesel e etanol.

O etanol pode ser produzido por vias químicas, pela fermentação direta de açucares ou por fermentação dos açucares de matérias primas mais complexas, como amido e celulose, após uma hidrólise enzimática ou química. Nesse último processo, contudo, a presença de lignina pode dificultar a produção de álcool, visto que esse composto não é degradável e está presente em grande proporção ( $25 \%$ a $30 \%$ do conteúdo mássico e $35 \%$ a $45 \%$ do conteúdo energético). Uma das alternativas é a gaseificação dessa biomassa para a produção de gás de síntese composto, em média, por $\mathrm{CO}, \mathrm{H}_{2}$ e $\mathrm{CO}_{2}$, e sua fermentação em outra etapa para a produção de etanol (Hickey et al., 2008; Kundiyana, 2010). 
Micro-organismos anaeróbios conseguem fermentar o gás de síntese e a partir disso produzir biocombustíveis como etanol, n-butanol e outros subprodutos como ácido acético, ácido butírico, entre outros (Hickey et al., 2008). Clostridium carboxidivorans é uma bactéria estritamente anaeróbia e gram-positiva (Pantaléon et al., 2014). As bactérias do gênero Clostridium são extremamente estáveis e podem ficar armazenadas por um ano sem perder sua atividade, além de ser tolerante a uma pequena exposição a oxigênio (em até $2 \%$ ).

Em relação aos processos bioquímicos de conversão, a fermentação usando o gás de síntese possibilita a eliminação de uma etapa complexa de pré-tratamento e custos altos com a obtenção de enzimas, como ocorre no processo de produção de etanol de segunda geração por rota enzimática. Além da conversão de todos os componentes celulósicos presentes no substrato, há também uma independência da composição dessa biomassa, bem como da relação $\mathrm{H}_{2}: \mathrm{CO}: \mathrm{CO}_{2}$ presente no gás de síntese (Shen et al., 2014).

Contudo, essa fermentação apresenta alguns fatores limitantes como a transferência de massa gás-liquido e a presença de alguns componentes inibidores no gás de síntese comercial, além de seu alto custo (Shen et al., 2014). A transferência de massa pode ser melhorada com o uso de células imobilizadas, como o caso do uso de reatores de membrana, que comprovadamente apresentam uma maior transferência entre as fases gasosa e líquida e dentro delas (Shen et al., 2014, Cross et al., 2012, Hickey et al., 2008).

Characklis e Marshall descreveram em oito passos o processo de formação de um biofilme bacteriano, desde a formação de uma camada "condicionada" até a dispersão das células da matriz subsequentemente a morte celular. Essa camada "condicionada" é a base para o crescimento do biofilme e é composta por várias moléculas orgânicas e inorgânicas devido à ação de forças gravitacionais ou do próprio movimento do fluído, o que modificará os substratos facilitando o acesso das células. A interação entre o substrato e a camada "condicionada" tem impactos na superfície, podendo alterar sua carga, potencial e tensão (Garrett et al., 2008).

As células livres então aderem à superfície condicionada de forma reversível, através da interação de forças físicas ou mesmo de estruturas da bactéria, como os flagelos. A energia disponível, a orientação da bactéria e condições de temperatura e pressão contribuem para a adesão. As forças que possibilitam o contato entre células e superfície são as forças de van der Waals, interações estéricas e interações eletrostáticas da camada dupla, e são explicadas pela teoria DVLO (Derjaguin-Landau-Verwey-Overbeek). Segundo essa, a direção da interação segue um balanço entre forças atrativas (van der Waals) e forças que são repulsivas (sobreposição da camada elétrica dupla da célula e do substrato) devido a carga elétrica negativa das células (Garrett et al., 2008).

A formação de biofilme propicia o aumento da concentração celular, contornando assim a dificuldade relacionada à baixa densidade celular em sistemas anaeróbios. Além disso, o biofilme traz diversos benefícios à cultura bacteriana diferente do que acontece em células livres. Bactérias aderidas a uma matriz apresentam maior resistência a danos por UV, gradientes de $\mathrm{pH}$ e a tensão de cisalhamento, o que oferece uma gama maior de condições operacionais em biorreatores. Por apresentarem maior resistência a poluentes e contaminantes, biofilmes são geralmente utilizados em plantas de tratamento de águas residuais. (Gross et al., 2012). 
O estudo da produção de etanol de segunda geração a partir do uso de gás de síntese tem sido bastante discutido nos últimos anos, principalmente relacionado a biofilmes. Em 2010, Munasinghe et al. conseguiram obter uma transferência de massa maior que a apresentada anteriormente na literatura ao realizar a fermentação do gás de síntese usando um biorreator de membrana de fibra oca compósita, sendo $946,6 \mathrm{~L} / \mathrm{h}$ o valor máximo para o coeficiente de transferência de massa volumétrica de CO. Na patente de Hickey et al. (2010), uma concentração de $20 \mathrm{~g} / \mathrm{L}$ foi obtida após 20 dias de produção contínua em reator de membrana de fibra oca de polipropileno. Em um estudo ainda mais recente, Shen et al. (2014) obteve uma produtividade máxima de 3,44 g/L.dia e 23,96 g/L de etanol com a mesma membrana de mesmo material.

Portanto, o objetivo desse trabalho é avaliar a adesão de células de C. carboxidivorans em diferentes membranas para futura aplicação das células aderidas em biorreatores de membrana para produção de etanol a partir de gás de síntese.

\section{MATERIAIS E MÉTODOS}

\subsection{Microrganismo}

A bactéria anaeróbia Clostridium carboxidivorans DSMZ 15243 foi adquirida pela empresa DSMZ (Leibniz Institute DSMZ-German Collection of Microorganisms and Cell Cultures). Essa é imóvel, gram-positiva e produtora de etanol, acetato, butirato e butanol. $\mathrm{O}$ intervalo ótimo de $\mathrm{pH}$ é de 5,0 a 7,0 e a temperatura ótima é de $37-40^{\circ} \mathrm{C}$.

\subsection{Gás De Síntese}

O gás de síntese empregado como substrato gasoso foi obtido na empresa White Martins Gases Industriais Ltda., sendo sua composição: $\mathrm{H}_{2}(40 \%), \mathrm{CO}(25 \%), \mathrm{CO}_{2}(10 \%), \mathrm{N}_{2}$ $(10 \%)$ e $\mathrm{CH}_{4}(11 \%)$.

\subsection{Membranas}

Para os ensaios de avaliação da formação de biofilme foram utilizados dois tipos de membranas de filtração fabricadas pela empresa Millipore e de diferentes características. A membrana HA em Éster de Celulose (código HAWP04700) é composta de nitrato e acetato de celulose e possui tamanho de poro $0,45 \mu \mathrm{m}, 79 \%$ de porosidade e caráter hidrofílico. A membrana FH (Fluorpore) (código FHLP04700) é composta de PTFE hidrofóbico com suporte de polipropileno de alta densidade, $0,50 \mu \mathrm{m}$ de tamanho de poro e $75 \%$ de porosidade.

As membranas foram inseridas em um frasco de penicilina anteriormente a adição de 50 $\mathrm{mL}$ de meio ATCC e gás de síntese. A esterilização do conjunto foi realizada em autoclave por $20 \mathrm{~min}$ a $0,5 \mathrm{~atm}$. Dois frascos contendo uma membrana de HA e uma $\mathrm{FH}$ cada não receberam inoculo. Esses frascos de controle também foram incubadas em shaker e denominados de HA branco e FH branco, respectivamente.

\subsection{Meios De Cultivo}


O meio utilizado para crescimento celular foi o ATCC 2713, composto de triptona $(10,00 \mathrm{~g} / \mathrm{L})$, peptona de digestão pancreática de gelatina $(10,00 \mathrm{~g} / \mathrm{L})$, extrato de lêvedo $(5,00$ $\mathrm{g} / \mathrm{L})$, glicose $(1,00 \mathrm{~g} / \mathrm{L})$, cloreto de sódio $(5,00 \mathrm{~g} / \mathrm{L})$, L-arginina $(1,00 \mathrm{~g} / \mathrm{L})$, piruvato de sódio $(1,00 \mathrm{~g} / \mathrm{L})$, menadiona $(0,0005 \mathrm{~g} / \mathrm{L})$ e hemina $(0,005 \mathrm{~g} / \mathrm{L})$ em $1000 \mathrm{~mL}$ de água deionizada. $\mathrm{O}$ $\mathrm{pH}$ final é ajustado para 7,1.

\subsection{Cultivo}

Foram inoculadas 5,00 mL de C. carboxidivorans cultivado em meio ATCC 2713 por $24 \mathrm{~h}$ a $37^{\circ} \mathrm{C}$ em frascos de penicilina contendo as membranas, o meio ATCC e o gás de síntese já previamente esterilizados em autoclave. Os frascos foram incubados em shaker a $150 \mathrm{rpm}$ e $37^{\circ} \mathrm{C}$ por 24 horas.

\subsection{Métodos Analíticos}

O crescimento celular no sobrenadante foi acompanhado através de medidas de densidade óptica a $600 \mathrm{~nm}$ e esses valores foram convertidos a gramas de peso seco de células por litro (g p.s. cél/L) utilizando-se o fator de conversão obtido pela curva de peso seco.

A quantificação do biofilme aderido à membrana foi feita através do método do peso constante. Primeiramente, as membranas foram pesadas antes de serem colocadas nos frascos e, após o crescimento celular, foram colocadas em contato com lâmpada infravermelho para secagem e subsequentemente pesadas.

\section{RESULTADOS E DISCUSSÃO}

A concentração celular de C. carboxidivorans em meio ATCC 2713 foi de 1,40 g p.s. cél/L no frasco contendo a membrana FH e $1,04 \mathrm{~g}$ p.s. cél/L no frasco com a membrana HA após $24 \mathrm{~h}$ de cultivo. O frasco de controle não apresentou crescimento visível e seu sobrenadante se manteve límpido. As massas das membranas determinadas antes do inoculo e após o cultivo podem ser verificados na Tabela 1.

É possível observar que a quantidade de células presentes no sobrenadante é maior do que o material depositado nas membranas. $\mathrm{O}$ frasco contendo a membrana $\mathrm{FH}$ apresenta uma massa celular de $0,0700 \mathrm{~g}$ enquanto sua respectiva membrana apresenta massa de material depositado de $0,0148 \mathrm{~g}$. O frasco com a membrana HA, por sua vez, apresentou 0,0520 g de células em seu sobrenadante, quantidade superior à da membrana, 0,0050 g. A maior disposição de células no sobrenadante se deve, provavelmente, a oferta de substrato no meio líquido e ao tempo do experimento, visto que além de atrações químicas, a força gravitacional é importante para a aderência e criação da camada "condicionada" e sem tempo suficiente, a adesão celular à superfície é comprometida.

Na Tabela 1, verifica-se que os frascos de controle apresentaram variação mássica. Eliminando-se o risco de contaminação devido às técnicas assépticas utilizadas em laboratório e baseando-se nos passos de Characklis e Marshall, é possível depreender que moléculas constituintes do meio aderiram a membrana por interações de caráter químico e por força gravitacional, como ocorre na camada "condicionada". Dessa forma, em "material depositado na membrana" considera-se a massa de células e de constituintes do meio. 
Tabela 1 - Massa das membranas Millipore FH (Fluorpore, código FHLP04700) e HA

(Éster de Celulose, código HAWP04700) antes do inoculo, após o inoculo de $C$.

carboxidivorans e do material depositado sobre sua superfície. As membranas $\mathrm{FH}_{\mathrm{B}}$ e $\mathrm{HA}_{\mathrm{B}}$ representam os brancos.

\begin{tabular}{cccc}
\hline Membrana & $\begin{array}{c}\text { Massa da } \\
\text { membrana após } \\
\text { inoculo (g) }\end{array}$ & $\begin{array}{c}\text { Massa da } \\
\text { membrana antes do } \\
\text { inoculo }(\mathbf{g})\end{array}$ & $\begin{array}{c}\text { Massa do material } \\
\text { depositado na membrana } \\
\mathbf{( g )}\end{array}$ \\
\hline FH & 0,1126 & 0,0978 & 0,0148 \\
\hline FH & 0,1015 & 0,0965 & 0,0050 \\
\hline HA & 0,0865 & 0,0811 & 0,0050 \\
\hline HA $_{\mathbf{B}}$ & 0,1037 & 0,0951 & 0,0086 \\
\hline
\end{tabular}

Considerando a massa do "material depositado na membrana" nos frascos $\mathrm{FH}_{\mathrm{B}}$ e $\mathrm{HA}_{\mathrm{B}}$ apenas como a massa de constituintes visto que não houve inoculo, é possível depreender a massa de células depositada e também a porcentagem do aumento mássico nas membranas em relação a células e a componentes do meio. Esses dados refletem claramente como a característica hidrofóbica e hidrofílica de cada membrana influencia tanto na aderência do biofilme quanto na aderência dos constituintes do meio.

Tabela 2 - Demonstrativo da massa do biofilme e porcentagens no aumento da massa nas membranas em relação às células e aos componentes do meio. É entendido como componente todos os demais constituintes do meio excetuando-se células.

\begin{tabular}{cccc}
\hline Membrana & $\begin{array}{c}\text { Massa de células } \\
(\mathbf{g})\end{array}$ & $\begin{array}{c}\text { Aumento na massa } \\
\text { (\% células) }\end{array}$ & $\begin{array}{c}\text { Aumento na massa (\% } \\
\text { componentes) }\end{array}$ \\
\hline FH & 0,0098 & 10,0204 & 5,1125 \\
\hline FH & 0,0000 & 0,0000 & 5,1813 \\
\hline HA & $-0,0032$ & $-3,9457$ & 10,6042 \\
\hline HA $_{\mathbf{B}}$ & 0,0000 & 0,0000 & 9,0431 \\
\hline
\end{tabular}

Shen et al. (2014) quando utilizando $C$. carboxidivorans para a produção de etanol através de um reator de membrana de fibra oca optaram pela utilização de membranas com caráter hidrofóbico. Em seu artigo, Garrett et al. (2008) afirmam que as propriedades hidrofóbicas e hidrofílicas de uma superfície têm grande influência na aderência celular. Os dados da Tabela 2 comprovam esse fato, visto que é possível observar que a membrana Fluorpore (FH) apresentou um aumento de massa celular $(10 \%)$ bem maior do que a membrana HA em Éster de Celulose, cujo aumento mássico relacionado à adesão microbiana foi inexistente. Além disso, esse caráter hidrofóbico também influenciou na deposição de constituintes do meio na membrana, o que pode ter impedido a aderência celular à superfície.

\section{CONCLUSÃO}

Foi possível concluir que membranas hidrofóbicas, como a Fluorpore, apresentam maior porcentagem em massa de células, sendo dessa forma mais favorável a formação de biofilme do que a membrana hidrofílica em Éster de Celulose. Apesar de a necessidade de 
maiores testes para a comprovação da influência dos constituintes do meio na formação do biofilme, foi possível observar que há deposição de material nas membranas além da adesão celular. Maiores estudos, contudo, devem ser realizados para que seja possível incrementar o aumento da espessura do biofilme bacteriano. Dessa forma, esses estudos iniciais se mostram promissores, visto que seus resultados vão de acordo com os vários estudos realizados nos últimos anos com relação à formação de biofilme, principalmente de bactérias e do gênero Clostridium, podendo assim otimizar sistemas de fermentação de gás de síntese para a formação de etanol.

\section{REFERÊNCIAS}

CARDINAL LAW GROUP. Evanston, IL. Robert Hickey, Rathin Datta, Shih-Perng Tsai, Rahul Basu. Membrane supported bioreactor for conversion of syngas components to liquid products. US 2008/0305539 A1, 11 dec. 2008.

KUNDIYAMA, D. K., HUHNKE, R. L., WILKINS, M. R. Syngas fermentation in a 100-L pilot scale fermentor: Design and process considerations. J. Biosci. Bioeng., v. 109, 492-498, 2010.

PANTALÉON, V., BOUTTIER, S., SOAVELOMANDROSO, A. P., JANOIR, C., CANDELA, T. Biofilms of Clostridium species. Anaerobe, xxx, p. 1-6, 2014.

SHEN, Y.; BROWN, R.; WEN, Z. Syngas fermentation of Clostridium carboxidivorans P7 in a hollow fiber membrane biofilm reactor: Evaluating the mass transfer coefficient and ethanol production performance. Biochem. Eng. J., v. 85, p. 21-29, 2014.

GROSS, R., SCHMID, A., BUEHIER, K. Catalytic Biofilms: A Powerful Concept for Future Bioprocess. In: LEAR, G., LEWIS, G. D. Microbial Biofilms: Current Research and Applications. Norfilk, UK. Caister Academic Press, 2012. p. 193-222.

MUNASINGHE, P. C., KHANAL, S. K. Syngas fermentation to biofuel: Evaluation of carbon monoxide mass transfer and analytical modeling using a composite hollow fiber (CHF) membrane bioreactor. Bioresour. Technol., v. 122, 130-136, 2012.

LIOU, J. S.C., BALKWILL, D. L., DRAKE, G. R., TANNER, R. S. Clostridium carboxidivorans sp. nov., a solvente-producing isolated from an agricultural settling lagoon, and reclassification of the acetogen Clostridium scatologenes strans SL1 as Clostridium drakei sp. nov. Int. J. Syst. Evol. Microbiol., v. 55, p. 2085-2091, 2005.

GARRETT, T. R., BHAKOO, M., ZHANG, Z. Bacterial adhesion and biofilms on surfaces. Prog. In Nat. Scienc., v. 18, p. 1049-1056, 2008. 